\title{
Evaluating and developing contraceptive services: The results of an audit of the North Lambeth Primary Care Commissioning Group
}

\author{
Caroline Free, MB ChB, DRCOG, DFP, MRCGP, MSc HSM, NHS Research and Development Primary Care Research Fellow, \\ Department of General Practice and Primary care, GKT School of Medicine, Kings College London, London, UK \\ Angela Dawe, MSc, Chief Executive: Sheeylar Macey, BA, RGN RSCN, FP901, Clinical Director, North Lambeth Primary Care \\ Group, London, UK \\ Caroline Mawer, MBBS, MFPHM, DRCOG, MSc, MFPHM, Consultant in Public Health Lambeth, Southwark and Lewisham Health \\ Authority, London, UK
}

Correspondence: Caroline Free, Department of General Practice and Primary Care, GKT School of Medicine, Kings College London, 5 Lambeth Walk. London SE11 6SP, UK. Tel: 02078409415

(Accepted July $13^{\text {th }}, 2000$ )

\begin{abstract}
Summary
Primary care groups are expected to meet the primary health care needs of their local population. In the inner-city London borough of Lambeth there are high levels of sexual health needs. The North Lambeth Primary Care Commissioning Group identified the evaluation and further development of contraceptive services, particularly to those under the age of 25, as a priority. An evaluation of current contraceptive service provision from general practice was carried out. The evaluation covered contraceptive service factors identified from the literature as linked to effective, acceptable, accessible and equitable service delivery. Factors linked to the effectiveness of services included service use, information provision, training of staff, provision of the full range of methods and services. Factors linked to the acceptability of services included confidentiality and the choice of the gender of the provider. The strengths and limitations of the data and indicators used are outlined. Areas requiring further evaluation are highlighted. The evaluation indicated scope for service development in all the key areas evaluated, and illustrated examples of good practice. For example, whilst information in practice leaflets and surgery waiting areas about the contraceptive services available was generally limited, one practice provided excellent information. Recommendations for service development were made covering information provision, staff training, and confidential access to services. These are being taken forward by an ongoing project.
\end{abstract}

\section{Key words}

family planning, family practice, medical audit, primary health care, urban health services

\section{Key message points}

- Primary care groups can successfully evaluate their contraceptive service provision.

- Scope for service development was highlighted in each of the areas evaluated.

- GP providers can successfully learn from each other and work together in developing their services.

- The data used in this evaluation provides a useful overview of needs and services. The data should be combined with further data collection, such as user views of services, to provide a full picture of services.

- Collaboration with other providers and agencies is needed to fully meet the needs of the under 24 year old population

\section{Introduction}

Primary care groups (PCGs) are expected to take on key roles in commissioning, clinical governance and professional self-regulation. They are expected to meet the primary health care needs of their local population. ${ }^{1}$

The population of the inner-city London Boroughs of Lambeth, Southwark and Lewisham (LSL) is relatively young, mobile, socially deprived and ethnically mixed. There are considerable sexual health and contraceptive service needs. The boroughs have one of the highest teenage pregnancy rates in Western Europe, and the highest rates of unplanned pregnancy in the UK. There are high fertility and abortion rates, and a high prevalence of sexually transmitted infections. ${ }^{2}$

The North Lambeth Primary Care Commissioning Group was set up in 1998 and identified the evaluation and development of contraceptive services to the under 25 year old population as a priority. In 1999 this group joined with 11 other general practices to become the North Lambeth Primary Care Group. One of the priorities of the North Lambeth Primary Care Group is to improve teenage sexual health and parenting skills. The North Lambeth PCG has taken on, and expanded, the work that the North Lambeth Primary Care Commissioning Group initiated in the area of contraception services. The first stage in addressing the development of services was evaluating current service provision by the North Lambeth Primary Care Commissioning Group. The rationale for the evaluation, the results, recommendations and action taken are presented Ongoing work and evaluations are being carried out by the North Lambeth Primary Care Group and cover all general practices in the North Lambeth Primary Care Group.

The evaluation framework

The framework for the evaluation covered the contraceptive service's effectiveness, acceptability, accessibility and equity. ${ }^{3}$ In the UK a direct effect of aspects of quality of contraceptive services on potential measures of effectiveness of services, such as contraception use or fertility rates, have not been shown. There is a lack of agreed quality standards for contraceptive services. ${ }^{4-7}$ Indicators of the effectiveness of contraceptive services proposed by the Faculty of Public Health include the abortion rate, abortion rate as a percentage of fertility rates, 
terminations after 12 weeks of gestation, and conceptions in those aged less than $16 .^{8}$ The international literature suggests that elements of service delivery resulting in effective services include information and communication, skilled and knowledgeable personnel, the availability of the full range of methods, ease of access, and confidentiality ${ }^{9-11}$

In keeping with this, in the UK, young people cite a desire for better information about contraceptives and services. ${ }^{12,13}$ Guidelines are in existence regarding the training and supervision of staff providing contraception services, although standards are not always met. ${ }^{14}$ Whilst $98 \%$ of GP surgeries offer some form of contraception, not all practices offer the full range of methods, or provide information regarding those that do. ${ }^{12-15}$ Factors reported to facilitate access to services for young people include having a walk-in service, opening in the late afternoons/ early evenings, and location. ${ }^{16}$ Factors related to the acceptability of services include confidentiality, staff having a friendly manner, and the choice of gender of provider. ${ }^{12,16}$ The full literature review, which informed the development of the evaluation framework outlined in Table 1 , is described elsewhere. ${ }^{17}$

In the evaluation a number of structure, process and outcome measures were used to evaluate the service factors linked to effective, accessible, acceptable and equitable service provision (Table 1). Available evidence suggests that the use of services, information provided by services, staff training, and availability of services are linked to the effectiveness of services, thus measures of these factors have been used as proxy measures for the effectiveness of services. The measures used were derived from routinely available data and some new data collection. Advantages and limitations of the measures used are outlined in the discussion.

\section{Method}

All 25 general practices in the Primary Care Commissioning Group agreed to share their data to enable the evaluation of contraceptive services and to participate in the project. Epidemiological data were obtained from the Office of National Statistics. The service data were obtained from the financial, service and prescribing data held by the Lambeth, Southwark and Lewisham Health Authority. Manual records of family planning clinics and Brook family planning services were obtained from these services. Each surgery waiting area was visited and practice leaflets were examined. Information regarding practice policies, staff training and service provision was obtained by telephoning practice managers or senior reception staff.

The Office for National statistics produces a number of data sets including birth and death files an mid-year population estimates by age group and sex, derived from census figures. They provide populat statistics for incidence rates of particular diseases, procedures (such as terminations of pregnancy) and birth rates.

at a All GP surgeries in the UK are required to record data on the service the number of patients registered by age and sex. Financial data is als de, for example payment to GPs is made when a financial claim for providing contraceptive services is made. A claim may be made for each woman for providing general contraceptive services (FP1001), for fitting a coil (FPI002) or for providing contraceptive services to a temporary qualifications of GPs, the opening times of GP surgeries, and should hold copies of current practice leaflets.

Prescriptions pricing authority data General practice prescribing data (PACT) is produced by the prescriptions pricing authority and produces data about the prescriptions dispensed as prescribed by each GP in each surgery.

Table 1 Aspects of contraceptive service provision evaluated

\begin{tabular}{|c|c|c|c|}
\hline Area of evaluation & What was evaluated & Source of data & What was measured \\
\hline \multirow[t]{2}{*}{ Effectiveness } & $\begin{array}{l}\text { Numbers and the proportion } \\
\text { of under } 25 \text { year olds using } \\
\text { services. }\end{array}$ & $\begin{array}{l}\text { Contraceptive claims } \\
\text { (FP1001/FP1002 data) }\end{array}$ & $\begin{array}{l}\text { Number of women aged } 16-24 \text { receiving contraceptive } \\
\text { services as a proportion of the number of women registered }\end{array}$ \\
\hline & & Practice list data & $\begin{array}{l}\text { Number of under } 16 \text { year old women receiving contraceptive } \\
\text { services }\end{array}$ \\
\hline Effectiveness & Information provision & $\begin{array}{l}\text { Leaflet } \\
\text { Visit to surgery premises }\end{array}$ & $\begin{array}{l}\text { Information regarding: } \\
\text { confidentiality of the service; emergency contraception; } \\
\text { provision to those aged less than } 16 \text { mentioned; choice of } \\
\text { method; choice of provider: in-house/ alternative provider; } \\
\text { times of availability. }\end{array}$ \\
\hline
\end{tabular}

Effectiveness Training of staff

Health authority held data

Telephone interview of practice manager

Effectiveness

Availability of full range of services

Acceptability Confidentiality

Choice of female provider
Prescribing data, contraceptive claims, (PACT, FP1001, FP1002)

Telephone interview of practice manager/senior receptionist As above

Telephone interview of practice manager/senior receptionist Leaflet, visit to surgery premises

Health authority data

Telephone interview of practice manager
GP qualifications DFFP/DRCOG/MRCG and certificate of competence in IUCD insertion

Nurse qualifications ENB 900/901/A08

Training of reception staff

Range of pills and injectable contraceptives prescribed. Provision of free condoms

Provision of immediate free pregnancy tests

Refusal to refer for moral/religious reasons and presence of alternative arrangements

Emergency appointments system, training of receptionists regarding confidentiality, information available regarding the confidentiality of the service

Qualified female provider

Opening times

Appointments or walk-in surgery

System for providing emergency contraception appointments whilst maintaining confidentiality 


\section{Calculation of the use of services}

The use of services was calculated according to the methods proposed by the Faculty of Public Health. ${ }^{8}$ Thus the number of women aged 16-24 using GP services was added to the number of women using family planning clinics. The number of women using both services was removed from this figure, which was then divided by the population of 1624 year olds registered with general practices in the area to give the proportion of women aged 16-24 using contraceptive services. The number of women in the different age groups using the GP services was calculated according to the number of contraceptive financial claims (FP1001/2/3). Figures of new attendances to the one Brook clinic within the area for the year were obtained from Brook. The existing family planning service figures for new attendances for the year had been collated for an area that was larger than the Primary Care Commissioning Group. The original records were accessed and the total number of new attendances for the year was calculated from this data for clinics operating in the primary care group area. The number of women using both services was calculated based on a recent local survey of women using family planning and GP contraceptive services. ${ }^{18}$ The population of women was calculated from practice list data. The estimated percentage of sexually active young women aged 12-15 was calculated based on surveys of sexual activity. The 1991 national survey of sexual behaviour found that $19 \%$ of those aged 16-19 at the time had been sexually active prior to the age of 16; a survey in Somerset found $46 \%$ of 16 year olds had experienced sexual intercourse. ${ }^{19,20}$ Neither study gives age-specific rates of sexual activity under the age of 16 . A recent survey in Scotland found that $15.4 \%$ of 13 and 14 year old girls had experienced sexual intercourse; $3.8 \%$ had sexual intercourse prior to the age of $13 .{ }^{21}$ A study based in North London found that $12 \%$ of 13 year olds, $17 \%$ of 14 year olds and $28 \%$ of 15 year olds had experienced sexual intercourse. ${ }^{22}$ Drawing on these surveys, the estimated proportion of sexually active teenagers was calculated based on the assumption that levels of sexual activity were $3.8 \%$ for 12 year olds, $15.4 \%$ for 13 year olds, $17 \%$ for 14 year olds and $28 \%$ for 15 year olds. The highest level of sexual experience was used when results varied, as high levels of teenage pregnancy in LSL suggest high levels of sexual activity. The figures may represent an overestimation of need for services as teenage sexual activity can be sporadic, and experience of sexual intercourse does not necessarily equate to current sexual activity.

Contraceptive service provision from different GP practices was assessed by measuring the number of financial claims made for contraceptives provided per 100 women registered in the 1997/98 financial year.

Information in the surgery waiting areas and in practice leaflets regarding contraception and contraceptive services was evaluated according to the criteria in Tables 4 and 5 . Practice managers/senior receptionists were interviewed by telephone regarding: the qualifications of staff; the availability of free condoms and free immediate pregnancy tests; whether all partners will refer for terminations of pregnancy and the alternative arrangements made, and the arrangements for providing appointments for emergency contraception needs.

Evaluation of equity was limited to an evaluation of equity in service provision in the different areas served by the different GP services. Evaluation of equity of service provision to different groups, and the cost effectiveness of services, was beyond the scope of this evaluation.

\section{Results \\ Effectiveness}

General measures of effectiveness are higher in LSL than in England and Wales (Table 2). Numbers of teenagers using contraceptive services and the uptake of contraceptive services as a proportion of the 16-24 year old female population are given in Table 3. Fifty-nine percent of 16-24 year old women resident in the North Lambeth Primary Care Commissioning Group area used contraceptive services. Fifty-two percent of the 12-15 year olds using services attended the one Brook clinic in the area. There are low numbers of teenagers under the age of 16 using services. Based on levels of sexual activity found in national and regional UK surveys, overall $16 \%$ of $12-15$ year olds are estimated to be sexually active, and $37 \%$ of these used services. There were no routine general practice data regarding contraceptive service provision to men. There was considerable variation in contraceptive service provision by the general practice (see Figure 1).

Table 2 Indicators of the effectiveness of contraceptive services

\begin{tabular}{|c|c|c|}
\hline & LSL & England and Wales \\
\hline Abortions per 1000 females & 33.3 & 12.1 \\
\hline Abortions per 1000 live births & 601 & 258 \\
\hline $\begin{array}{l}\text { Percentage of terminations of } \\
\text { pregnancy carried out after } 12 \text { weeks } \\
\text { Conception rates per } 1000 \text { females }\end{array}$ & 19.0 & 11.4 \\
\hline aged $11-15$ & 7.0 & 3.4 \\
\hline
\end{tabular}

This data is produced by the ONS and has crown copyright.

Information. Information on contraceptive service provision in practice leaflets and surgery waiting rooms was assessed according to the criteria in Table 1 (see Tables 4 and 5 for the results). One practice leaflet provided all the information sought. There was generally limited information available in waiting rooms.

Skilled and fully informed personnel. In the majority of practices more than one GP or all GPs had postgraduate training in family planning (Table 6). One practice had noone with postgraduate family planning training. According to contraceptive claims (FP1002), some GPs are only fitting one or two coils per year.

Receptionists in three practices had received specific training regarding condom distribution, sexual health services or emergency contraception. Eight surgeries had regular updates with receptionists or verbal policies regarding the provision of emergency appointments for emergency contraception.

Availability of the full range of methods and services According to practice leaflets and prescribing data, not all practices fit caps, coils or prescribe the contraception injection. Fourteen $(56 \%)$ of practices provide free condoms. One surgery gave the phone number of an alternative provider for emergency contraception in their practice leaflet. Free and immediate pregnancy tests are available from some surgeries. Other surgeries provide them only for medical emergencies and teenagers. Three surgeries make a charge for non-'medically urgent' pregnancy testing.

Two practices had partners who, for moral or religious reasons, did not make referrals for termination of pregnancy. In both cases alternative provision was made. Neither practices provided information in the practice leaflet or surgery premises about this. 
Table 3 The use of contraceptive services by women in the Primary Care Commissioning Group for the financial year 1997/98

\begin{tabular}{|c|c|c|c|c|c|c|c|}
\hline $\begin{array}{l}\text { Age } \\
\text { (years) }\end{array}$ & $\begin{array}{l}\text { Number of } \\
\text { women using } \\
\text { the GP family } \\
\text { planning service } \\
(\%)\end{array}$ & $\begin{array}{l}\text { Number of } \\
\text { Women using } \\
\text { the community } \\
\text { family planning } \\
\text { service } \\
(\%)\end{array}$ & $\begin{array}{l}\text { Percentage of } \\
\text { women using } \\
\text { both services }^{18}\end{array}$ & $\begin{array}{l}\text { Percentage of } \\
\text { women living } \\
\text { outside the area } \\
\text { but using the } \\
\text { community family } \\
\text { planning service }\end{array}$ & $\begin{array}{l}\text { Number of women } \\
\text { living in LSL } \\
\text { receiving services } \\
\text { in the areai }\end{array}$ & $\begin{array}{l}\text { Numbers of } \\
\text { women resident }{ }^{\mathrm{iii}} \\
\text { (number of } \\
\text { women estimated } \\
\text { to be sexually } \\
\text { active) }\end{array}$ & $\begin{array}{l}\text { Percentage of } \\
\text { women using } \\
\text { contraceptive } \\
\text { services } \\
\text { (\% of estimated } \\
\text { sexually active } \\
\text { women using } \\
\text { services) }\end{array}$ \\
\hline $12-15$ & $\begin{array}{r}27 \\
(15 \%)\end{array}$ & $\begin{array}{c}158 \\
(85 \%)\end{array}$ & 2 & 10 & 166 & $\begin{array}{l}2789 \\
(448)\end{array}$ & $\begin{array}{c}6 \\
(37)\end{array}$ \\
\hline $16-24$ & $\begin{array}{r}3305 \\
(64 \%)\end{array}$ & $\begin{array}{l}1843 \\
(36 \%)\end{array}$ & 10 & 10 & 4811 & 8100 & 59 \\
\hline $16-44$ & $\begin{array}{l}13381 \\
(75 \%)\end{array}$ & $\begin{array}{l}4367 \\
(25 \%)\end{array}$ & 10 & 10 & 21639 & 35500 & 60 \\
\hline
\end{tabular}

Data is missing from one surgery due to organisational changes taking place in the practice during 1997/98

$\overline{\mathrm{i}}$ This figure included only those who received contraception from the family planning or Brook service, not all new attendees. It is likely to be lower than the total figure receiving advice. Brook figures for the year are provisional.

ii The numbers of women obtaining services form A\&E and sexual health clinics is small

iii The number of women aged 12-15 was calculated as 3/5 of the $10-14$ year old population and $1 / 5$ of the 15 to 19 year old population registered in the practices evaluated.

\section{Accessibility}

All general practices were open in the late afternoon/ early evening, with 14 practices having walk-in surgeries at these times. Other surgeries had appointments only, or a mixture of appointments and emergencies.

\section{Acceptability}

Confidentiality. Two practices described a strict policy that receptionists do not question patients regarding the nature of an urgent appointment. Other practice managers described a process whereby women who need emergency contraception are 'fitted in', which means that in some circumstances the patient needs to tell the receptionist the nature of the appointment.

Choice of female provider. Three practices had no female partner or nurse qualified in family planning.

\section{Equity}

The data show that there is a local lack of equity in service provision and illustrates that younger teenagers may not use services. It was not possible to evaluate service provision to different ethnic groups using the routine data. Locally, an interpreting service provides interpreters for over 40 different languages, but there was no up to date written information in any language other than English.

\section{Discussion of the evaluation}

An evaluation of contraceptive service provision across the Primary Care Commissioning Group was completed within a short period of time (6 weeks). The evaluation should not be considered to be exhaustive, but it does provide an overview of services and indicate areas for further evaluation or service development. It provides a baseline assessment of the services provided by general practices so that individual practices can compare themselves to the average and/ or best practice. It also enables GP surgeries to be aware of changes in their services over time when reevaluation occurs.

The evaluation leaves specific gaps, as there is a limited range of routine data available. The gaps include non-user/ user views of local GP services and important service

Figure 1 Distribution of the percentage of women aged 16-24 in each practice receiving contraception from primary care. [Data from one practice is missing due to organisational changes in the practice during 1997/8.]

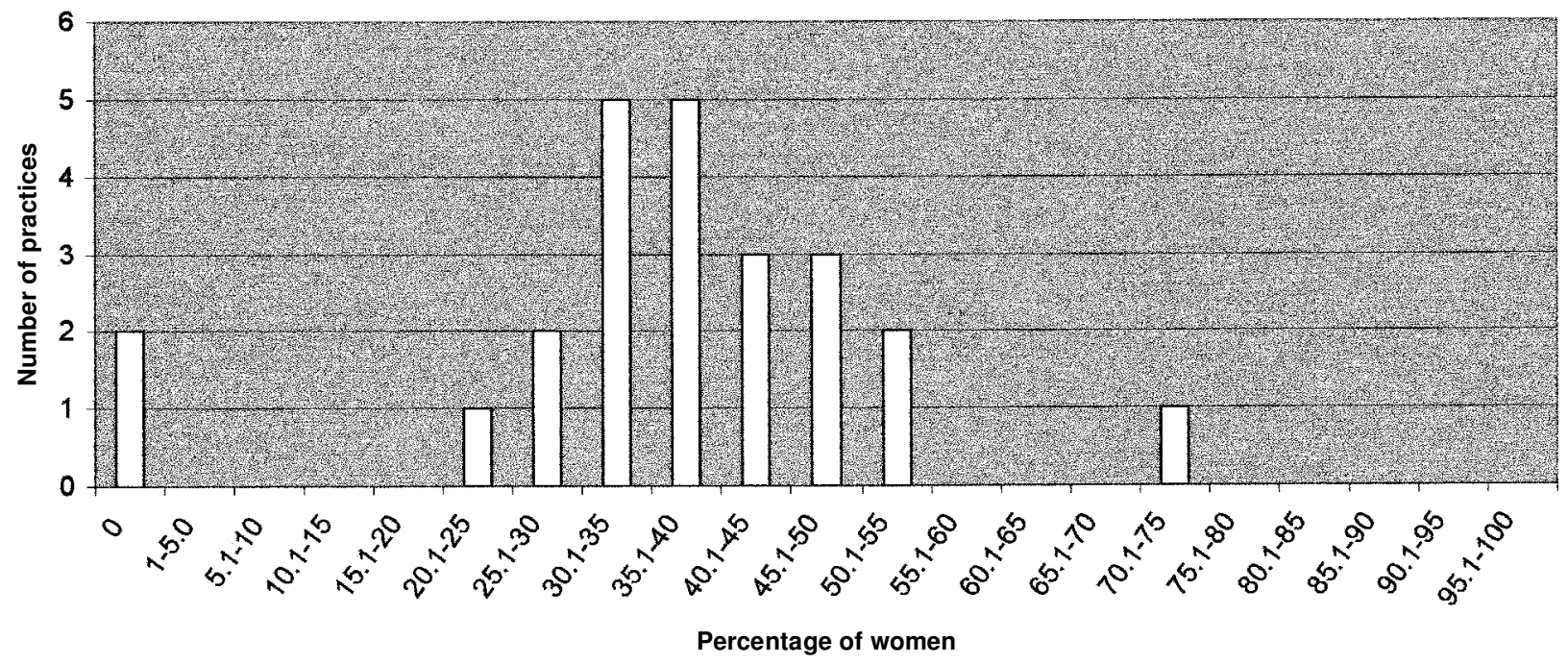


Table 4 Information on display in surgery waiting areas

\begin{tabular}{ll}
\hline Area information covers & $\begin{array}{l}\text { Percentage of surgeries providing } \\
\text { information }(\mathrm{n}=21)\end{array}$ \\
\hline Family planning & $81 \%(17)$ \\
Emergency contraception & $28 \%(6)$ \\
$\begin{array}{l}\text { Confidentiality } \\
\text { How to access the service }\end{array}$ & $14 \%(3)$ \\
$\begin{array}{l}\text { How to obtain an emergency } \\
\text { appointment }\end{array}$ & $19 \%(4)$ \\
$\begin{array}{l}\text { Condoms } \\
\text { Availability of a young persons }\end{array}$ & $24 \%(5)$ \\
$\begin{array}{l}\text { service } \\
\text { Availability of an alternative service } \\
\text { provider (includes family planning } \\
\text { provided by all other sexual health } \\
\text { services) }\end{array}$ & $0 \%(0)$ \\
\end{tabular}

One surgery premise was excluded due to building work.

Some practices shared premises and waiting areas.

Data collected 97/98.

factors such as communication. The evaluation of the service's confidentiality, acceptability and equity in provision to different groups is limited.

There are a number of limitations to the measures derived from routine data relating to their validity, sensitivity, specificity and the data quality. The measures used represent a necessary compromise between the quantitative data easily or routinely available, and the essential features of good indicators. ${ }^{23,24}$

The validity of measures is reduced by an indirect link between some of the data available and the information desired. Termination rates, for example, are proxy indicators of unwanted pregnancy and are inaccurate in that not all pregnancies ending in termination are originally unplanned, and not all pregnancies continuing to term are originally planned. All of the measures using a population denominator use the total number of women in the age group and not the number of women at risk of pregnancy. The sensitivity of abortion rates and fertility rates as measures of the effectiveness of services are reduced as they are all influenced by a range of social, educational and personal factors as well as by services. These measures may be more appropriately interpreted as measures of 'contraceptive service' need. High termination rates may also reflect a high quality termination of pregnancy service rather than poor contraceptive services.

The evaluation uses contraceptive service financial claims (FP1001/2) as a measure of service use. Financial claims data are not, however, independently verified and do not necessarily relate directly to the quality of the contraceptive advice. Less financially efficient practices, for example, may provide services without making financial claims. The figures for service use illustrate the use of family planning, Brook and GP services in the area and do not include measures of the use of condoms purchased from chemists or machines. There are no data regarding condoms provided by general practice, and no routine data regarding contraception services provided to men from general practices. The family planning clinic data are not held by postcode, so it was not possible to exclude those women receiving services from family planning clinics within the area who live outside the area. There were no available data regarding women living in the area receiving family planning services outside the area. The percentage of women using services, and the percentage of women years of contraceptives prescribed, both used the practice population of women as the denominator.
However, within LSL list sizes may be as much as $10 \%$ inflated across age bands compared to population estimates derived from census data. ${ }^{25}$ The number of woman years of contraceptives prescribed, which can be calculated from non-age specific prescribing data, was not calculated in the initial evaluation. It would provide a useful comparison to financial claims data.

The data were not always complete or accurate. For example, some practice leaflets were unobtainable. These factors should be taken into consideration when drawing conclusions form the results of the evaluation.

\section{Discussion of the results}

General measures of the effectiveness of services indicate high levels of unmet need in the area of contraception. Reasonably high service contact, as measured by contraception claims, suggests that focusing on improving the service provided will be an effective strategy for reaching the majority of young women. Just over half of the under 16 year olds using services use the Brook clinic. In keeping with other data, this suggests that Brook has been relatively successful in reaching this age group. It is likely that lessons could be learned from their service approach. The perceived anonymity and confidentiality of the service is likely to remain an important factor. ${ }^{9,11,12}$ The calculations suggest that over half the sexually active under 16 population are not using any service. This is in keeping with national data and research, which suggest that specific youth services and collaboration with others (schools, youth workers, family planning services, Brook services) may be required to reach younger teenagers. ${ }^{16}$ The family planning service opened one teenage clinic in late 1997. It is important that the different services collaborate in providing information regarding specific youth services, and in providing information about family planning and Brook clinics, which may be perceived to be more anonymous and therefore acceptable to younger teenagers. ${ }^{16}$

Young men have high levels of sexual health education and service (including contraception services) needs. There are no routine data regarding the use of GP services for sexual health matters by young men, and few young men attend general practice. Providing suitable services for young men remains relatively under evaluated and addressed. Development of suitable services should form part of the North Lambeth Primary Care Group sexual health strategy. ${ }^{26}$

Information. The results of the evaluation indicate considerable scope for improved information provision regarding the services available, alternative providers and features of the service, in both practice leaflets and surgery

Table 5 Information available in practice leaflets

\begin{tabular}{lc}
\hline Area of Information & $\begin{array}{r}\text { Percentage of practice leaflets } \\
(\mathrm{n}=22)\end{array}$ \\
\hline Family planning mentioned & $91 \%(20)$ \\
Confidentiality & $41 \%(9)$ \\
Emergency contraception & $23 \%(5)$ \\
Choice of method & $36 \%(8)$ \\
Choice of provider (in house) & $23 \%(5)$ \\
Choice of alternative provider & $32 \%(7)$ \\
Provision for those aged less than & \\
16 specifically mentioned & $4 \%(1)$ \\
Times of availability & $32 \%(7)$
\end{tabular}

*Three practice leaflets were unavailable.

Data according to practice leaflets available by $31 / 8 / 98$. 
Table 6 Table of staff training and available services

\begin{tabular}{|c|c|c|c|c|c|}
\hline $\begin{array}{l}\text { Number of practices } \\
(\%)\end{array}$ & $\begin{array}{l}\text { GP family planning } \\
\text { qualification }\end{array}$ & $\begin{array}{l}\text { Practice nurse family } \\
\text { planning qualification }\end{array}$ & $\begin{array}{c}\text { Availability of free } \\
\text { condoms }\end{array}$ & $\begin{array}{c}\text { Availability of free } \\
\text { immediate pregnancy } \\
\text { tests }\end{array}$ & $\begin{array}{l}\text { All partners will refer } \\
\text { patients for termination }\end{array}$ \\
\hline $\begin{array}{l}\text { Total positive responses } \\
(\%)\end{array}$ & $\begin{array}{c}21 \\
(84 \%)\end{array}$ & $\begin{array}{l}16 \\
(64 \%)\end{array}$ & $\begin{array}{l}16 \\
(64 \%)\end{array}$ & $\begin{array}{c}17 \\
(68 \%)\end{array}$ & $\begin{array}{c}23 \\
(92 \%)\end{array}$ \\
\hline $\begin{array}{l}\text { Total negative responses } \\
(\%)\end{array}$ & $\begin{array}{c}3 \\
(12 \%)\end{array}$ & $\begin{array}{c}6 \\
(24 \%)\end{array}$ & $\begin{array}{c}9 \\
(36 \%)\end{array}$ & $\begin{array}{c}8 \\
(32 \%)\end{array}$ & $\begin{array}{c}2 \\
(8 \%)\end{array}$ \\
\hline $\begin{array}{l}\text { No information available } \\
(\%)\end{array}$ & $\begin{array}{c}1 \\
(4 \%)\end{array}$ & $\begin{array}{c}3 \\
(12 \%)\end{array}$ & 0 & 0 & 0 \\
\hline Total & $\begin{array}{c}25 \\
(100 \%)\end{array}$ & $\begin{array}{c}25 \\
(100 \%)\end{array}$ & $\begin{array}{c}25 \\
(100 \%)\end{array}$ & $\begin{array}{c}25 \\
(100 \%)\end{array}$ & $\begin{array}{c}25 \\
(100 \%)\end{array}$ \\
\hline
\end{tabular}

This data was collected by telephone interview with practice managers/ senior receptionists and from health authority held data during July and August 1998

waiting areas. The literature indicates that there is a considerable lack of knowledge regarding contraception, emergency contraception, confidentiality and available local services amongst young people. ${ }^{27-28}$ The Primary Care Group has drawn up guidelines indicating the information that should be available. The example of excellent information provided by one practice, with a special interest in sexual health, has been disseminated to other practices. An insert for practice leaflets providing information has been developed. A re-evaluation of leaflets and waiting areas is planned.

Skilled and fully informed personnel. A number of GPs and many practice nurses did not have specific training in family planning. Some surgeries locally are fitting only one or two coils per year, which is less than the Faculty of Family Planning recommends in order to maintain competence. Guidelines regarding the appropriate GP and nurse training and updating should be made. Limited training places available to practice nurses means that priority should be given to those in a surgery where there is no trained female provider. Receptionists require training regarding confidentiality, condom provision and urgent contraception appointments.

Availability of the full range of methods and services. Not all methods are available in all practices, but there is a wide range of contraceptive service provision per practice according to prescribing and contraceptive financial claims data (Figure 1). This should be addressed by a combination of training and referral between different service providers to ensure that all women have access to all services. The insert for practice leaflets, developed since the evaluation, advertises alternative in-house or out-of-house providers covering the full range of methods. Information should be available to patients regarding whether or not health care professionals make referrals for termination of pregnancy.

Accessibility. The appointments and emergency appointments system provided by some general practices may make services less accessible to young women with urgent contraceptive needs. This especially applies if the appointments system does not allow confidentiality to be maintained.

Acceptability. Confidentiality regarding the nature of the need for an emergency appointment was not maintained at the receptionist's desk in all surgeries. For young people confidentiality is a key issue, and a system needs to be devised where by they can feel confident in asking for an urgent appointment for emergency contraception without being questioned about the nature of their visit. The choice of a female provider should be offered in-house or, if this is not possible, by giving information regarding other providers.

Equity. The variation in provision of contraceptive services between practices (Figure 1) is in keeping with known variation in provision of primary care services. Improving lower levels of service provision, whilst maintaining and encouraging innovation and excellence, is one of the key challenges to the development of primary care services in inner London. The unequal service provision will be partially addressed by the recommendations made and by easy access to alternative providers if a particular service is not provided by an individual or surgery. Equity in the use of services by different subgroups, such as the homeless or ethnic minorities, requires specific evaluation.

Overview. The evaluation was able to provide a broad overview of current contraceptive service provision. Recommendations for contraceptive service development were made, which are being taken forward by the ongoing project. To date, guidelines have been developed and agreed, good practice has been disseminated, and a practice leaflet insert setting out all family planning services in Lambeth has been produced. Areas for further assessment have been highlighted, a questionnaire survey regarding clinical standards is in process, an evaluation of contraceptives prescribed from general practice has been carried out and a follow up evaluation planned.

\section{Conclusion}

The evaluation has been a useful tool, providing a broad overview of service provision in one geographical area. The evaluation identified scope for service development in all key areas evaluated, and highlighted areas for further evaluation and action. Recommendations were made which have been taken forward by the Primary Care Group.

The predominant reliance on routinely available data leaves scope for further evaluation in areas such as user views of the service's acceptability and accessibility.

General practices from one geographical area worked in collaboration and shared data to enable the evaluation phase to take place. They have been able to compare their service provision with the average and/or best practice in the Primary Care Commissioning Group. They continue to collaborate in the development phase. It would be feasible for similar evaluations to be carried out by other Primary Care Groups.

\section{Recommendations}

The Primary Care Group should:

- focus on improving services to the majority of women already using them 
- identify means of working in collaboration with other groups (e.g. schools, family planning services, Brook clinics and youth workers) to address the needs of younger teenagers

- draw up guidelines indicating the information that should be available in leaflets and waiting areas

- agree PCG standards for nurse and GP family planning qualifications

- increase the availability of the full range of methods and services through training and providing information and easy access to alternative providers

- arrange training for receptionists (especially regarding confidentiality)

- encourage GP surgeries to develop systems that enable confidential access for urgent contraception needs

- offer the choice of a female provider either in-house or, if this is not possible, by providing information regarding other services.

\section{Statement on funding and competing interest \\ Funding: None}

Competing interests: None declared

\section{Contributions}

The literature review, evaluation and recommendations to the Primary Care Group were carried out by Caroline Free and were submitted as her MSc project at the London School of Hygiene and Tropical Medicine. Sheeylar Macey collected data from half the surgery waiting areas. Angela Dawe and Sheeylar Macey are jointly responsible for the ongoing developmental work and further evaluations. Caroline Mawer facilitated access to the relevant data and staff at the Health Authority and has been responsible for further evaluations in Lambeth Southwark and Lewisham.

\section{Acknowledgements}

Thanks are due to all the GP surgeries in the Primary Care Group who are collaborating in this project, and to the staff at Lambeth, Southwark and
Lewisham Health Authority who facilitated access to the data. Particular thanks is due to Sheila Challenger.

Chisholm J. Primary care and the NHS white papers. BMJ 1998; 316: 1687-688. Lambeth, Southwark and Lewisham. Lambeth, Southwark and Lewisham Health Action Zon Partnership Bid. 199

Maxwell R. Quality assessment in health. BMJ 1984; 288: 1740-741.

Smith C. Measuring quality in contraceptive services. Quality in Health Care 1997; 6: 59. Harris J, Peckham S, Walsh J. Defining quality in family planning services. Brit J Obs and Gynae 1996; 103: 1109-116.

6 FPA. Family planning services: a model for district health authorities. London: FPA, 1990

the effectiveness of contraceptive services. Guidelines for Health promotion No37, 1994 .

Jain A, Bruce J, Mensch B. Setting standards of quality in family planning programmes. Ahlies in F, Kelley A, P $1990 ; 20$ : 1

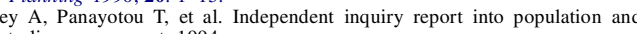

(Buce J. Fundamental elements of quality of care; a simple framework. Studies in Family Planning 1990; 21: 61-89.

2 Cooper P, Diamond I, Gould C, et al Choosing and using contraceptives: consumer experiences in Wessex. Southampton: University of Southampton, 1992

Epstein R, Rice P, Wallace P. Teenagers health concerns: implications for primary care professionals. JRCGP 1989; 39: 247-249.

14 Chambers R, Milsom G. Survey of contraceptive services and extent of staff qualifications in family planning in primary care in Staffordshire. Br J Fam Plann. 1996; 22: 186-188.

Cooper P, Diamond I, High S, et al. A comparison of family planning provision: general practice and family planning clinics. Br J Fam Plann:19: 263-269.

16 Peckham S, Ingham R, Diamond I. Teenage pregnancy: prevention and programmes. Institute

7 Free C. How can the North Lambeth Primary Care Commissioning Group improve their contraceptive service provision to the under twenty-five-year-old population? London: Londo chool of Hygiene and Tropical Medicine, 1998.

18 Keyes-Evans O. An evaluation of family planning clinic services. Submission for part II of the membership of the faculty of public health medicine. Feb 1998

Wellings K, Field J, Johnson A, Wadsworth J. Sexual Behaviour in Britain. London: Penguin, 1994

20 Ford N, Halliday J, Little J. Changes in drug use and sexual lifestyles in young people in

1 Wight D, Henderson M, Raab G, et al. Extent of regretted sexual intercourse among young teenagers in Scotland: a cross sectional survey. BMJ 2000; 320: 1243-244.

22 Burack R. Teenage sexual behaviour: attitudes towards and declared sexual activity. Br J Fam Plann 1999; 24: 145-148.

McKee M, Routine data: a resource for clinical audit? Quality in Health Care 1993; 2 $104-111$.

24 Kane R, Wellings K, Free C, Goodrich J. Uses of routine data in the evaluation of health promotion interventions: opportunities and limitations. Health Education 2000; 100 (1): 33-41.

25 Challenger S, Information manager, Health Policy, Lambeth, Southw ark and Lewisham Health Authority. Personal communication. 1999

26 National Children's Bureau. Forum fact sheet 11: Supporting the needs of boys and young men in sex and relationships education. Sex Education Forum. London: National Children' Bureau, 1997.

27 Whitlow B, Desmond N, Hay P. Pregnant teenagers and contraception. BMJ. 1995; 311: 806 Graham A, Green L, Glasier A. Teenager's knowledge of emergency contraception questionnaire survey in SE Scotland. BMJ 1996: 312: 1567-569. 